\title{
Retinal ischemic syndrome-digestive tract small vessel hyalinosis-diffuse cerebral calcifications syndrome
}

INSERM

\section{Source}

INSERM. (1999). Orphanet: an online rare disease and orphan drug data base. Retinal ischemic syndrome-digestive tract small vessel hyalinosis-diffuse cerebral calcifications syndrome. ORPHA:3018

Retinal ischemic syndrome-digestive tract small vessel hyalinosis-diffuse cerebral calcifications syndrome is characterized by progressive hyalinosis involving capillaries and often arterioles and small veins of the digestive tract, kidneys, and idiopathic cerebral calcifications. It has been described in three sisters born to non-consanguineous parents. All three patients also had poikilodermia and greying hair, as well as severe diarrhoea, rectal bleeding, malabsorption and subarachnoid hemorrhage. 